I. Brusca ${ }^{1}$, S. Graci ${ }^{2}$, M. Barrale ${ }^{1}$, G. Cammilleri ${ }^{2}$, M. Zarcone ${ }^{3}$, R. Onida ${ }^{1}$, A. Costa ${ }^{2}$, V. Ferrantelli² ${ }^{2}$ M.D. Buscemi², C.G. Uasuf ${ }^{4}$, M. Gjomarkaj ${ }^{4}$, M. Vazzana ${ }^{5}$, S.M. La Chiusa $^{1}$, G. Iacolino ${ }^{1}$, F. Vitale ${ }^{3}$, W. Mazzucco ${ }^{3}$

\title{
Use of a comprehensive diagnostic algorithm for Anisakis allergy in a high seroprevalence Mediterranean setting
}

${ }^{1}$ Clinical Pathology Buccheri La Ferla Hospital, Palermo, Italy

${ }^{2}$ National Reference Centre for Anisakiasis, Istituto Zooprofilattico Sperimentale della Sicilia A. Mirri, Palermo, Italy ${ }^{3}$ Department of Science for Health Promotion and Mother to Child Care G. D’Alessandro, University of Palermo, Palermo, Italy. Clinical Epidemiology and Cancer Registry Unit, P. Giaccone University Hospital, Palermo, Italy.

${ }^{4}$ Allergy Diseases Center G. Bonsignore, Institute of Biomedicine and Molecular Immunology A. Monroy (IBIM), National Research Council (CNR), Palermo, Italy

${ }^{5}$ STEBICEF Department, University of Palermo, Palermo, Italy

\section{KEY WORDS}

anisakis; food allergy; diagnosis of anisakis sensitization; basophil activation test; Immunocap

\section{Corresponding author}

Ignazio Brusca

Clinical Pathology Buccheri La Ferla

Hospital, Palermo

Via Messina Marine, 197

90123, Palermo, Italy

E-mail: ignbr@libero.it

\section{Doi}

10.23822/EurAnnACI.1764-1489.118

\begin{abstract}
Summary
Background. Diagnosis of anisakis allergy (AA) is based on the skin prick test (SPT) and specific IgE (sIgE) determination. Anyway, false positivity cases are due to cross reactivity with numerous allergens. The aim of the study was to evaluate the reliability of a comprehensive diagnostic algorithm for the AA. Methods. An observational study was conducted on a sample of consecutive subjects accessing the allergology outpatient ambulatories of two hospitals located in Western Sicily. All the recruited outpatients were tested by Skin Prick Test performed using anisakis extracts by ALK-Abellò (Madrid, Spain). Specific IgE dosage for anisakis extracts was then performed by using ImmunoCAP250 (Immunodiagnostics Uppsala, Sweden). Consequently, outpatients who tested positive to first line tests underwent sIgE testing for ascaris and tropomyosin. Lastly, outpatients positive to the first line were invited to be further tested by basophil activation test (BAT) by using Flow CAST kit and anisakis commercial extract (Bühlmann Laboratories AG, Schönenbuch, Switzerland), as confirmatory analysis. Results. One hundred and eleven outpatients with an anamnesis suggestive of sensitization to anisakis $(A S)$ and 466 subjects with chronic urticaria (CU) were recruited in the study. Of these, 22 with $A S$ and 41 with $C U$ showed a sensitization to anisakis allergens. The diagnostic algorithm revealed that $8.8 \%$ of outpatients who tested positive to sIgE determination were affected by $C U$, while $82.5 \%$ of all the sIgE positivity was related to cross-reactivity. Overall, a genuine anisakis seroprevalence of $2.3 \%$ was documented. Within a sub-sample of 15 subjects with clinical symptoms related to $A A, n .8$ showed a real positivity after $B A T$. A greater response to $A$. pegreffi allergens as compared to $A$. simplex was reported. Conclusions. Our preliminary findings support the high clinical specificity of BAT for AA diagnosis, suggesting implementing this method in a comprehensive diagnostic algorithm.
\end{abstract}




\section{Introduction}

The increasing habits of eating uncooked, raw or marinated sea fish, made human exposure to Anisakis an issue of public health concern, so that European Food Safety Agency (EFSA, 2010) included this parasite among the most significant biological hazards in seafood (1). Particularly, the consumption of marinated or raw fish has been demonstrated to enhance the risk of sensitization to Anisakis (2). According to these widespread alimentary habits, Japan is one of the countries with the highest worldwide prevalence of Anisakiasis cases (2-3). A high Anisakis seroprevalence was reported in countries overlooking the Mediterranean Sea, such as Morocco, Spain, Croatia and Italy, where consumption of marinated or raw sea fish belongs to adept-rooted culinary tradition, especially in coastal communities (4-6). However, given the high prevalence of sea fish parasitized by Anisakis spp. in the Mediterranean Sea (7-9), the impact of Anisakiasis and Anisakis sensitization could be underestimated. More recently, transcriptomic studies on the characterization of Anisakidae species have identified 36 potential allergens for A. simplex s.s. and 29 for $A$. pegreffii (10), suggesting a possible improvement in the detection of allergenic response and in the definition of the epidemiology of Anisakis-related diseases.

Anisakiasis, in some case, is accompanied by mild or severe allergic symptoms (ranging from urticaria-angioedema to anaphylaxis), with no digestive manifestations, being in any case the gastroscopy the gold standard for its diagnosis (11). In sensitized subjects, allergic manifestations can occur even without infestation, as reported by several authors (3,11-13). Of interest, some Anisakis allergens have been found to be heat-stable so that cooking the fish could not prevent the allergenicity of the parasite (14-16).

To date, the diagnosis of Anisakis allergy has raised some criticism due to the low specificity and sensibility of the diagnostic methods based on the allergenic extract currently available. More in depth, diagnosis includes anamnesis (ingestion of fresh fish a few hours before the reaction) and in vivo skin prick test (SPT), confirmed with in vitro detection of specific IgE by serum immunoassay (2,18-19). Anyway, false positivity cases are frequent due to the cross reactivity with numerous pan allergens (2,18-21). Anisakis sensitization can occur by exposure to species-specific allergenic molecules such as Ani s1, Ani s4 and Ani s7, or to cross-reactive muscle proteins of other organisms such as tropomyosin and paramyosin, having a strong molecular and immunological cross-reactivity with other invertebrates, including crustaceans and dust mites (17-19,22-23). Further, cross-reactive molecules are the SXP/RAL family proteins, similar to the ones of other nematodes (18-21). Therefore, diagnosis of Anisakis allergy aims to discriminate between "genuine" sensitization and cross-reactivity with all of the mentioned molecules. Of interest, for SXP/RAL proteins IgE Anisakis: Ascaris (An: As) ratio was considered a reliable tool to evaluate possible cross-reactions to other nematodes, whereas recent studies confirmed that an $\operatorname{IgE}$ An:As ratio $\geq 4.2$ can increase the specificity of the test to $95 \%$ in subjects with specific Ascaris-IgE $\geq 0.35$ (24). Moreover, despite the absence of clinical symptoms, healthy individuals may have high levels of specific IgE for Anisakis allergens and vice versa (1). Several studies indicated that 16 to $22 \%$ of blood donors had specific IgE for Anisakis $(5,25)$. Another study reported that about $24 \%$ of subjects with acute urticaria showed a SPT positivity and/or specific IgE for Anisakis, although Anisakis was the real triggering cause only in 33\% of cases (26). Consequently, there is a need to distinguish Anisakis allergy from sensitizations to other allergenic sources that are often incorrectly diagnosed. The gold standard for food allergy is the challenge with food allergens, but ethical reasons do not allow the performance of this test in case of Anisakis allergy suspect (27-30).

Basophil Activation Test (BAT) has been proposed as a reliable tool for Anisakis allergy, integrating standardized procedures (skin prick test and specific IgE dosage) both at diagnosis and follow-up, but evidences in support of that are scant (8,31-32). In Sicily, the largest island in the Mediterranean Sea, there is a high Anisakis seroprevalence of $15.4 \%$ which was recently reported in a sample of patients with mono-sensitization to the nematode (33).

An observational study was conducted on a sample of subjects accessing two allergology outpatient ambulatories sited in Palermo, Western Sicily, Italy, with the aims i) to assess validity and clinical specificity of a comprehensive diagnostic algorithm for Anisakis allergy, including SPT, IgE specific dosage for Anisakis extracts, as a first approach, followed by $\operatorname{IgE}$ specific for Ascaris tropomyosins and use of BAT, as confirmatory analysis, ii) to highlight any difference of sensitization between $A$. pregreffi $i$ and $A$. simplex s.s., species prevalent in fish in the Atlantic Ocean and in the Mediterranean Sea, respectively, and iii) to understand how this difference can affect the results of the diagnosis.

\section{Materials and methods}

\section{Subjects in study}

Consecutive subjects accessing the allergology outpatient ambulatories of Fatebenefratelli Buccheri la Ferla Hospital and of IBIM Research National Council of Palermo, both located in Palermo (Western Sicily, Italy), were recruited in this cross-sectional study between January 2016 and May 2017. Inclusion criteria were 1) an anamnesis suggestive of sensitization to Anisakis (AS) in individuals reporting acute clinical manifestation in the last month due to allergic reactions (asthma, rhinitis, conjunctivitis, urticaria/angioedema, abdominal pain, diarrhea, vomiting or anaphy- 
laxis) after eating fresh fish or in subjects at high risk exposure to contact with sea products and abstaining from fish ingestion; 2) a $>6$ weeks documented spontaneous urticaria, defined as chronic urticaria $(\mathrm{CU})$, presenting with or without angioedema. To this end, a structured questionnaire was designed to collect the characteristics of the outpatients (age, sex, area of residency) together with anamnesis information, and then administered to all the subjects accessing the ambulatories during the study period. Exclusion criteria were a fish sensitization documented by diagnostic testing. Starting from the routinely diagnostic approach, the following comprehensive diagnostic algorithm (figure 1) was applied to the subjects included in the study according to anamnesis. As first line the outpatients were tested by SPT and IgE specific dosage for Anisakis extracts. Consequently, outpatients positive to first line tests underwent IgE specific testing for Ascaris and tropomyosins (second line) and were further checked for Dermatophagoides pteronyssinus (D1) IgE positivity.
Lastly, the outpatients who tested positive to the first line were invited to be further tested by BAT, as confirmatory experimental analysis. To this end, only a sub-sample of 13 outpatients answered to the call. Moreover, despite testing negative at the first line and also to a sardine prick-by-prick test, two more subjects, documenting a very suggestive clinical presentation for Anisakis allergy, were also tested by BAT. Overall, a sub-sample of 15 outpatients was tested by BAT.

\section{Informed consent}

All outpatients have read and signed an informed consent before the blood sampling and the questionnaire administration. The study was performed with the approval of the ethics committee of Policlinico Giaccone Hospital, Palermo, Italy $(8 / 2018-10 / 09 / 2018)$ and was in agreement with the Helsinki Declaration.

Figure 1 - Flow chart of the comprehensive algorithm applied for the diagnosis of Anisakis allergy.

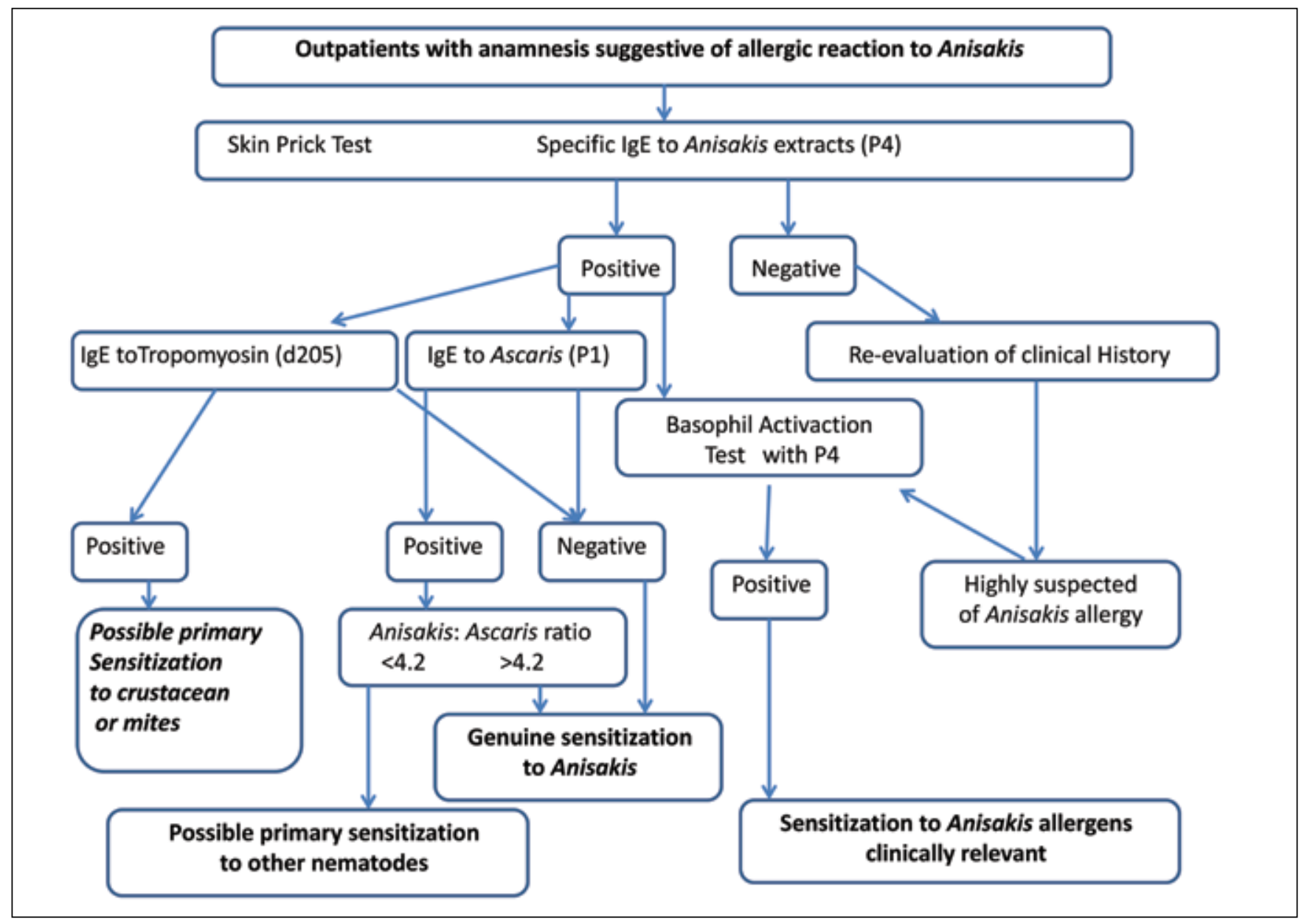




\section{Anisakis protein extraction and species identification}

Proteins' extraction from $A$. pegreffii and $A$. simplex s.s. was carried out both for SPT and BAT analysis using about 50 larvae per species collected after visual inspection from Lepidopus caudatus (high presence of $A$. pegreffi) and Cluepea harengus (high presence of A. simplex s.s.) fish samples (34). Anisakis larvae were stored overnight (o.n.) in test tubes with distilled water at $-80^{\circ} \mathrm{C}$ and later subjected to tissues lysis. A mechanical lysis was conducted by glass potters with the addition of $1 \mathrm{ml}$ of PBS ( $\mathrm{pH} 7$ ). Subsequently, the fragmented larvae were subjected to 3 sonication cycles of 30 seconds. The homogenized larvae were placed on a vertical rotor at $+4{ }^{\circ} \mathrm{C}$ o.n., then centrifuged at 16,000 revolutions per minute (rpm) for 15 minutes for the supernatant collection, containing the crude extract. Protein concentration was assessed by Quibit 2.0 fluorimeter (Invitrogen, Carlsbad, California, USA). Anisakis larvae used for protein extraction were further analyzed for species identification by Polymerase chain reaction with Restriction Fragment Length Polymorphism (PCR-RFLP) method, according to the protocols reported in literature (10).

\section{Current diagnostic approach}

Skin Prick Test was performed using Anisakis extracts by ALKAbellò (Madrid Spain). A positive result was defined by the presence of a wheal $\geq 3 \mathrm{~mm}$ in diameter. Specific IgE dosage (ImmunoCAP250, Immunodiagnostics Uppsala, Sweden) was then performed for Anisakis (p4), tropomyosin (Der p10-d205), Ascaris (p1) to reveal an Anisakis positivity, and for cod (f3), tuna (f40) and carp parvalbumin (Cyp c1-f355) allergens to diagnose a fish allergy. A specific IgE amount $>0.35 \mathrm{kIU} / \mathrm{L}$ was considered positive. In addition, a parasitological examination of the feces was carried out to verify any presence of nematodes.

\section{Basophil activation test}

Basophil activation test was performed according to the manufacturer's instructions, by using Flow CAST kit and Anisakis commercial extract (Bühlmann Laboratories AG, Schönenbuch, Switzerland), namely Bühlmann extract (B.e.). BAT homemade allergenic extracts were obtained from Anisakis pegreffii (A.p.e.) and Anisakis simplex s.s. (A.s.e.) as described above. For each type of allergen used in BAT, a dose response curve was implemented at the following concentrations: $112.5 \mathrm{ng} / \mathrm{ml}, 22.5$ $\mathrm{ng} / \mathrm{ml}, 4.5 \mathrm{ng} / \mathrm{ml}, 0.9 \mathrm{ng} / \mathrm{ml}$. A threshold of $15 \%$ of activated basophils was considered positive.

\section{ImmunoCAP inhibition assay}

In order to assess the cross reactivity in the A.p.e. and A.s.e. extracts, a specific pool was derived from the sera of the 15 in- dividuals tested by BAT and then used to perform CAP-inhibition at $-20^{\circ} \mathrm{C}$, according to the method described by Savi et al (35). Two $100 \mathrm{~mL}$ aliquots per sera were incubated separately for $12 \mathrm{~h}$ at $4^{\circ} \mathrm{C}$ with $200 \mathrm{ml}$ of A.p.e. and A.s.e. extracts at increasing dilutions $(0 \mu \mathrm{g} / \mathrm{ml} ; 25 \mu \mathrm{g} / \mathrm{ml} ; 50 \mu \mathrm{g} / \mathrm{ml} ; 100 \mu \mathrm{g} / \mathrm{ml} ;$ $200 \mu \mathrm{g} / \mathrm{ml}$ ). Then, sIgE against Anisakis were determined and the inhibition effect was computed using the following formula: $\%$ inhibition $=100-(\mathrm{IgE}$ inhibited sample $(\mathrm{kU} / \mathrm{l}) \times 100 / \mathrm{IgE}$ anti-Anisakis (kU/l) at zero concentration of larvae extracts).

\section{Statistical analysis}

Absolute and relative frequencies for qualitative variables and mean \pm standard deviation (SD) for continuous variables were calculated as descriptive statistics of the subject's characteristics. Chi-square test was used to compare the two outpatients' groups (Anisakis allergy suspected versus chronic urticaria) for categorical variables, while t-test was performed to make comparisons for continuous variables.

In order to describe the distribution of percentages of BAT using B.e., in the sub-sample of 15 outpatients, a violin plot with box-wishers and individual values was drawn. To further compare in the 15 outpatients the two homemade allergenic extracts (A.p.e versus A.s.e.) by different concentration values, and their 95\% confidence intervals, the non-parametric Kruskal-Wallis rank sum test was performed. Iteration between types of extracts and concentrations was tested as well. A significance level p-value $<0.05$ was considered for statistical analysis. Descriptive statistical analysis, Chi-square and Student's t tests were performed by MedCalc ${ }^{\circledR}$ software. The non-parametric analysis of variance and the violin plot were performed using RStudio (version 1.1.383) [RStudio Team (2016). RStudio: Integrated Development for R. RStudio, Inc., Boston, MA URL http:// www.rstudio.com/] for the statistical software $\mathrm{R}$ (version 3.4.3) [R Core Team (2017)]. R: A language and environment for statistical computing. R Foundation for Statistical Computing, Vienna, Austria. URL https://www.R-project.org/.

\section{Results}

In table I are summarized the characteristics of the 577 outpatients (n. 433, 75.0\% females), mean age $37.6(\mathrm{SD} \pm 20)$, recruited in the study. Of these, 111 (19.2\%), mean age 36.4 $(\mathrm{SD} \pm 15)$, documented an anamnesis suggestive of AS, while n. $466(80.8 \%)$, mean age $38.2(S D \pm 20)$, were affected by a documented CU. There was no statistically significant difference between the two groups by age ( $\mathrm{p}$-value $>0.05)$ nor gender ( $\mathrm{p}$-value $>0.05)$. Outpatients with an anamnesis suggestive of AS were more frequently residents in coastal areas (26; $22.5 \%)$ as compared to ones affected by CU (43; 9.2\%) (p-value 0.0002$)$. A positive SPT was documented in $59(10.2 \%)$ 
Table I - Characteristic of 577 outpatients enrolled in the study to investigate for Anisakis sensitization status.

\begin{tabular}{|c|c|c|c|c|}
\hline Characteristic & Total & $\begin{array}{c}\text { Anamnesis suggestive for Anisakis } \\
\text { sensitization }\end{array}$ & Chronic urticaria & p-value \\
\hline n. $(\%)$ & $577(100 \%)$ & $111(19.2 \%)$ & $466(80.8 \%)$ & \\
\hline female n. (\%) & $433(75.0 \%)$ & $84(75.7 \%)$ & $349(74.9 \%)$ & \multirow{2}{*}{$>0.05$} \\
\hline male n. (\%) & $144(25.0 \%)$ & $27(24.3 \%)$ & $117(25.1 \%)$ & \\
\hline urban & $442(76.6 \%)$ & $74(66.7 \%)$ & $368(78.9 \%)$ & \multirow{3}{*}{0.0002} \\
\hline inland & $66(11.4 \%)$ & $11(9.9 \%)$ & $55(11.8 \%)$ & \\
\hline coastal & $69(11.9 \%)$ & $26(22.5 \%)$ & $43(9.2 \%)$ & \\
\hline \multicolumn{5}{|c|}{ skin prick test n. (\%) } \\
\hline Total & $577(100 \%)$ & $111(100 \%)$ & $466(100 \%)$ & \\
\hline \multicolumn{5}{|l|}{ specific IgE n. (\%) } \\
\hline positive & $63(10.9 \%)$ & $22(19.8 \%)$ & $41(8.8 \%)$ & \multirow{2}{*}{0.001} \\
\hline negative & $514(89.1 \%)$ & $89(90.2 \%)$ & $425(91.2 \%)$ & \\
\hline Total & $577(100 \%)$ & $111(100 \%)$ & $466(100 \%)$ & \\
\hline
\end{tabular}

of the 577 recruited outpatients, while an $\operatorname{IgE}$ positivity was detected in $63(10.9 \%)$ subjects of the study sample. SPT positivity resulted significantly higher in subjects with an anamnesis suggestive of AS $(20 ; 18.1 \%)$ than in the ones affected by CU (39; $8.4 \%)$ ( $\mathrm{p}$-value 0.01 ). Along the same lines, an IgE positivity was more frequently documented in outpatients suspected to be sensitized to Anisakis $(22 ; 19.8 \%)$ as compared to $\mathrm{CU}$ outpatients $(41 ; 8.8 \%)$ (p-value 0.001$)$. Furthermore, all of the SPT positive patients tested positive to Anisakis IgE, while 36 outpatients resulted positive to F40, F3 and F355.

In Table $\mathbf{2}$ is reported the distribution of $\operatorname{IgE}$ specific positivity by tropomyosin, Ascaris and Anisakis only in outpatients with an anamnesis suggestive for Anisakis sensitization as compared to outpatients with a documented chronic urticaria. No statistically significant difference between the two groups was reported for tropomyosin $\mathrm{IgE}$ positivity (p-value 0.07) and Ascaris $\operatorname{IgE}$ positivity ( $\mathrm{p}$-value 0.123 ). Instead, a statistical difference was highlighted in the distribution of Anisakis only $\operatorname{IgE}$ positivity (p-value 0.012). Overall, a genuine Anisakis seroprevalence of $2.3 \%$ was documented in the study sample (table II).

In table III are shown the results of the application of the comprehensive diagnostic algorithm on the sub-sample of 15 outpatients, 9 from the group of subjects with an anamnesis suggestive of AS and 6 from the CU group. Within the first group,
7 subjects (A, B, C, D, G, H, I) were positive to the first line diagnosis, while of the two negative outpatients with an anamnesis highly suggestive of Anisakis allergy one (E) tested negative to SPT and IgE but tested positive to BAT only, and the other subject (F) tested negative to all the tests. Ascaris IgE was positive in 3 outpatients (A, D, G) and the $\operatorname{IgE}$ An:As ratio resulted higher than 4.2. None of the tested subjects from the CU group resulted positive to BAT. Within this group, Ascaris $\mathrm{IgE}$ were positive in 2 outpatients $(\mathrm{N}, \mathrm{Q})$, with one $(\mathrm{N})$ showing an $\operatorname{IgE}$ An:As ratio equal to 9.96, while the other one (Q) documented an IgE An:As ratio of 0.63 . Overall, 8 outpatients (A, B, C, D, E, G, H, I) tested positive to BAT.

In Table IV is reported the comparison of basophil activation test performed between B.e. (commercial extract) and A.s.e. and A.p.e. (homemade extracts) in the sub-sample. Four outpatients (A, B, G, I) tested positive to all the extracts, three $(\mathrm{C}, \mathrm{E}, \mathrm{H})$ were reactive to B.e., while only one (D) documented a positivity to A.p.e. Moreover, three BAT positives subjects $(\mathrm{G}, \mathrm{H}, \mathrm{I})$ didn't document any clinical sign or symptom after ingestion of sea products. Of the remaining individuals, seven outpatients tested negative to BAT, one (F) belonged to the AS group, while 6 subjects (M, N, O, P, Q, L), clinically negative to fish products allergy, were from the CU group: 3 simple chronic urticaria $(\mathrm{M}$, $\mathrm{N}, \mathrm{Q}), 2$ chronic urticaria with associated atopic dermatitis $(\mathrm{O}$, 
Table II - Distribution of IgE specific positivity by a) Tropomyosin, b) Ascaris and c) Anisakis in 111 outpatients with an anamnesis suggestive for Anisakis sensitization compared to 466 outpatients with a documented chronic urticaria.

\begin{tabular}{|c|c|c|c|c|c|}
\hline & Specific IgE & Total & $\begin{array}{l}\text { Anamnesis suggestive for } \\
\text { Anisakis sensitization } \\
\text { n. }(\%)\end{array}$ & $\begin{array}{l}\text { Chronic urticaria n. } \\
(\%)\end{array}$ & p-value \\
\hline \multirow{3}{*}{ a } & positive for tropomyosin & $32(5.5 \%)$ & $10^{1}(9.0 \%)$ & $22^{2}(4.7 \%)$ & \multirow{2}{*}{0.07} \\
\hline & negative for Anisakis and Ascaris & $545(94.5 \%)$ & $101^{3}(91.0 \%)$ & $444^{4}(95.3 \%)$ & \\
\hline & Total & $577(100.0 \%)$ & $111(100.0 \%)$ & $466(100.0 \%)$ & \\
\hline \multirow{3}{*}{ b } & positive for Ascaris & $18(3.1 \%)$ & $\begin{array}{l}6 \\
(5.4 \%) \\
\end{array}$ & $12(2.6 \%)$ & \multirow{2}{*}{0.123} \\
\hline & $\begin{array}{l}\text { negative for Anisakis and } \\
\text { tropomyosin }\end{array}$ & $559(96.9 \%)$ & $\begin{array}{l}105 \\
(94.6)\end{array}$ & $454(97.4 \%)$ & \\
\hline & Total & $577(100.0 \%)$ & $111(100.0 \%)$ & $466(100.0 \%)$ & \\
\hline \multirow{3}{*}{ c } & positive for Anisakis only & $13(2.3 \%)$ & $6(5.4 \%)$ & $7(1.5 \%)$ & \multirow[b]{2}{*}{0.012} \\
\hline & $\begin{array}{l}\text { negative for Ascaris and } \\
\text { tropomyosin }\end{array}$ & $564(97.7 \%)$ & $105(94.6 \%)$ & $459(98.5 \%)$ & \\
\hline & Total & $577(100.0 \%)$ & $111(100.0 \%)$ & $466(100.0 \%)$ & \\
\hline
\end{tabular}

Dermatophagoides pteronyssinus (D1)

${ }^{1} \mathrm{D} 1=\mathrm{n} .10 / 10(100 \%) ;{ }^{2} \mathrm{D} 1=$ n. $22 / 22(100 \%) ;$ p-value $>0.05 ;$

${ }^{3} \mathrm{D} 1$ = n. 36/101 (35.6\%); ${ }^{4} \mathrm{D} 1$ = n. 192/444 (43.2\%); p-value 0.16;

Table III - Application of the comprehensive diagnostic algorithm (experimental lab analysis) on the sub-sample of 15 outpatients.

\begin{tabular}{|c|c|c|c|c|c|c|c|c|c|}
\hline Subject & anamnesis & age & $\operatorname{sex}$ & SPT & $\begin{array}{c}\text { IgE1 } \\
\text { Anisakis } \\
\text { kU/L }\end{array}$ & $\begin{array}{c}\mathrm{IgE1} \\
\text { tropomyosin } \\
\mathrm{kU} / \mathrm{L} \\
\end{array}$ & $\begin{array}{c}\text { IgE1 Ascaris } \\
\mathrm{kU} / \mathrm{L}\end{array}$ & $\begin{array}{l}\text { Anisakis / Ascaris } \\
\text { IgE ratio }\end{array}$ & BAT \\
\hline A & $\begin{array}{c}\text { urticaria } \\
\text { angioedema }\end{array}$ & 69 & $\mathrm{f}$ & + & 98.2 & 0.0 & 8.96 & 10.95 & $\mathrm{p}$ \\
\hline $\mathrm{B}$ & $\begin{array}{c}\text { anaphylaxes } 3^{\circ} \\
\text { grade }\end{array}$ & 52 & $\mathrm{f}$ & + & 6.87 & 0.0 & 0.0 & - & $\mathrm{p}$ \\
\hline $\mathrm{D}$ & $\begin{array}{c}\text { diarrhoea and } \\
\text { urticaria }\end{array}$ & 10 & $\mathrm{~m}$ & + & 0.6 & 3.14 & 1.32 & 0.45 & $\mathrm{p}$ \\
\hline $\mathrm{E}$ & $\begin{array}{c}\text { urticaria } \\
\text { angioedema }\end{array}$ & 68 & $\mathrm{~m}$ & - & 0.0 & 0.0 & 0.0 & - & $\mathrm{p}$ \\
\hline $\mathrm{F}$ & $\begin{array}{c}\text { urticaria } \\
\text { angioedema }\end{array}$ & 41 & $\mathrm{f}$ & + & 0.01 & 0.01 & 0.01 & - & $\mathrm{n}$ \\
\hline $\mathrm{H}$ & no symptoms & 27 & $\mathrm{~m}$ & + & 1.09 & 0.02 & 0.0 & - & $\mathrm{p}$ \\
\hline $\mathrm{I}$ & no symptoms & 43 & $\mathrm{f}$ & + & 7.9 & 0.0 & 0.0 & - & $\mathrm{p}$ \\
\hline $\mathrm{L}$ & $\begin{array}{c}\text { chronic urticaria } \\
\text { with atopic } \\
\text { dermatitis }\end{array}$ & 55 & $\mathrm{f}$ & + & 0.8 & - & 0.1 & 8.0 & $\mathrm{n}$ \\
\hline
\end{tabular}


Table III - (continued)

\begin{tabular}{|c|c|c|c|c|c|c|c|c|c|}
\hline Subject & anamnesis & age & $\operatorname{sex}$ & SPT & $\begin{array}{c}\text { IgE1 } \\
\text { Anisakis } \\
\text { kU/L }\end{array}$ & $\begin{array}{c}\text { IgE1 } \\
\text { tropomyosin } \\
\text { kU/L }\end{array}$ & $\begin{array}{c}\text { IgE1 Ascaris } \\
\mathrm{kU} / \mathrm{L}\end{array}$ & $\begin{array}{c}\text { Anisakis / Ascaris } \\
\text { IgE ratio }\end{array}$ & BAT \\
\hline M & chronic urticaria & 74 & $\mathrm{f}$ & + & 0.76 & 0.0 & 0.04 & 19.0 & $\mathrm{n}$ \\
\hline $\mathrm{N}$ & chronic urticaria & 64 & $\mathrm{f}$ & + & 54.5 & 0.0 & 5.47 & 9.96 & $\mathrm{n}$ \\
\hline $\mathrm{P}$ & $\begin{array}{c}\text { urticaria } \\
\text { angioedema } \\
\text { and idiopathic } \\
\text { anaphylaxes }\end{array}$ & 46 & $\mathrm{f}$ & + & 0.03 & 0.0 & 0.0 & 0.0 & $\mathrm{n}$ \\
\hline
\end{tabular}

${ }^{1}$ The diagnostic cut-off of the specific $\operatorname{IgE}$ is $0.35 \mathrm{kU} / \mathrm{L}$.

SPT, skin prick test; BAT, basophil activation test; P, positive; N, negative.

Table IV - Comparison of Basophil Activation Test results between Bühlmann extract and homemade extracts.

\begin{tabular}{|c|c|c|c|c|c|c|c|c|c|c|}
\hline \multirow[t]{2}{*}{ Subject } & \multirow[t]{2}{*}{ anamnesis } & \multicolumn{9}{|c|}{ BAT1 (\%) } \\
\hline & & $\begin{array}{l}\text { B.e. } \\
22.5 \mathrm{ng} / \\
\mathrm{ml}\end{array}$ & $\begin{array}{l}\text { A.p.e. } \\
112.5 \mathrm{ng} / \\
\mathrm{ml}\end{array}$ & $\begin{array}{l}\text { A.p.e. } \\
22.5 \\
\mathrm{ng} / \mathrm{ml}\end{array}$ & $\begin{array}{l}\text { A.p.e. } \\
4.5 \\
\text { ng/ml }\end{array}$ & $\begin{array}{l}\text { A.p.e. } \\
0.9 \\
\mathrm{ng} / \mathrm{ml}\end{array}$ & $\begin{array}{l}\text { A.s.e. } \\
112.5 \\
\mathrm{ng} / \mathrm{ml}\end{array}$ & $\begin{array}{l}\text { A.s.e. } \\
22.5 \\
\mathrm{ng} / \mathrm{ml}\end{array}$ & $\begin{array}{l}\text { A.s.e. } \\
4.5 \\
\mathrm{ng} / \mathrm{ml}\end{array}$ & $\begin{array}{l}\text { A.s.e. } \\
0.9 \\
\text { ng/ml }\end{array}$ \\
\hline A & urticaria angioedema & 84.4 & 75.5 & 79.9 & 75.1 & 53.3 & 84.5 & 80.0 & 72.3 & 32.4 \\
\hline B & anaphylaxes $3^{\circ}$ grade & 70.1 & 83.6 & 75.4 & 58.6 & 20.8 & 43.6 & 28.0 & 3.5 & 0.0 \\
\hline $\mathrm{E}$ & urticaria angioedema & 39.5 & 0.8 & 0.6 & 0.4 & 0.0 & 2.2 & 1.3 & 0.5 & 5.7 \\
\hline $\mathrm{F}$ & urticaria angioedema & 1.2 & 0.74 & 0.81 & 0.0 & 0.0 & 0.0 & 0.39 & 0.0 & 0.0 \\
\hline G & $\begin{array}{l}\text { clinical symptoms without } \\
\text { eating fish }\end{array}$ & 55.2 & 84.1 & 75.1 & 61.0 & 16.2 & 44.5 & 10.0 & 1.1 & 0.7 \\
\hline $\mathrm{L}$ & $\begin{array}{l}\text { chronic urticaria with atopic } \\
\text { dermatitis }\end{array}$ & 0.8 & 1.7 & 0.2 & 0.0 & 0.0 & 0.3 & 1.8 & 0.2 & 0.0 \\
\hline M & chronic urticaria & 0.8 & 0.0 & 0.6 & 0.0 & 0.6 & 0.6 & 0.0 & 0.0 & 0.9 \\
\hline $\mathrm{N}$ & chronic urticaria & 2.3 & 0.0 & 0.0 & 0.0 & 0.0 & 0.0 & 0.0 & 0.0 & 0.0 \\
\hline $\mathrm{O}$ & atopic & 4.3 & 0.0 & 0.0 & 0.0 & 0.0 & 0.0 & 0.0 & 0.0 & 0.0 \\
\hline $\mathrm{P}$ & $\begin{array}{l}\text { urticaria angioedema and } \\
\text { idiopathic anaphylaxes }\end{array}$ & 4.7 & 2.8 & 0.0 & 0.0 & 0.0 & 8.8 & 3.9 & 0.0 & 0.0 \\
\hline Q & chronic urticaria & 0.0 & 0.0 & 1.9 & 0.0 & 0.0 & 0.9 & 1.1 & 0.0 & 0.0 \\
\hline
\end{tabular}

${ }^{1}$ The diagnostic cut off of the BAT is $15 \%$ of activated basophiles.

BAT, basophil activation test; B.e., Bühlmann extract; A.p.e., Anisakis pegreffii extracts; A.s.e., Anisakis simplex sensu stricto extracts. 
L), and 1 with urticaria angioedema and idiopathic anaphylaxes (P). Furthermore, according to our findings, B.e. tends to act as a greater basophil activator compared to the homemade extracts at the concentration of $22.5 \mathrm{ng} / \mathrm{ml}$.

The violin plot depicts the distribution of detected basophiles activation percentages, tested by Bühlmann extract, in the sub-sample of 15 outpatients (figure 2). The empirical kernel density estimate clearly shows the diversity in the distribution between positive and negative values. Furthermore, within the positive outpatients, except for one subject being slightly over the diagnostic cut-off of $15 \%$, percentages of detected basophiles activation were consistently high.

Lastly, an homologous inhibition higher than $70 \%$ was determined by A.p.e and A.s.e at $50 \mu \mathrm{g} / \mathrm{ml}, 100 \mu \mathrm{g} / \mathrm{ml}$ and $200 \mu \mathrm{g} /$ $\mathrm{ml}$ concentrations, but at $25 \mu \mathrm{g} / \mathrm{ml}$ the A.p.e. shows an higher inhibition than the A.s.e. (figure 3).

\section{Discussion}

We conducted a cross-sectional study with the aims to assess the reliability of a comprehensive diagnostic algorithm for Anisakis allergy, including BAT as confirmatory analysis, and to evaluate if the exposure to the different Mediterranean Sea (A. pregreffii) and Atlantic Ocean (A. simplex s.s.) species could affect the re- sults of the test. For this purpose, a sample of consecutive subjects accessing two outpatient allergology ambulatories located in Western Sicily, one of a general hospital and another from a research center, was recruited in the study.

The proposed diagnostic algorithm is based on cost-effective tests, commercially available, including specific $\operatorname{IgE}$ to investigate any possible cross reaction plus an "in vitro" simulation of allergenic challenge by BAT. We haven't used the commercially available microarray ISAC (Immunodiagnostics Uppsala, Sweden), that contains Ani s1 (specific of Anisakis spp.) and Ani s3 (tropomyosin), because this assay is very expensive and no data on its diagnostic accuracy have been reported. By contrast, other tropomyosins, presenting a high analytical accuracy and about $70 \%$ of sequence homology, are available for ImmunoCAP platform at cheaper prices (17-18). Therefore, we cannot exclude a residual misdiagnosis. In particular, it was conceived to overcome three issues related to the diagnosis of Anisakis allergy: 1) the molecular allergenic expression of this nematode ranges from specific epitopes to several cross reactive proteins that causes a lack of specificity in routinely testing; 2) few and insufficient allergenic molecules are commercially available to perform a more accurate diagnosis: 3) the double blind placebo controlled food challenge (DPFCC), gold standard in food allergy diagnosis, is not applicable. Applying the commonly used

Figure 2 - Distribution of detected basophils activation percentages, tested by Bühlmann extract, in the sub-sample of n. 15 outpatients.

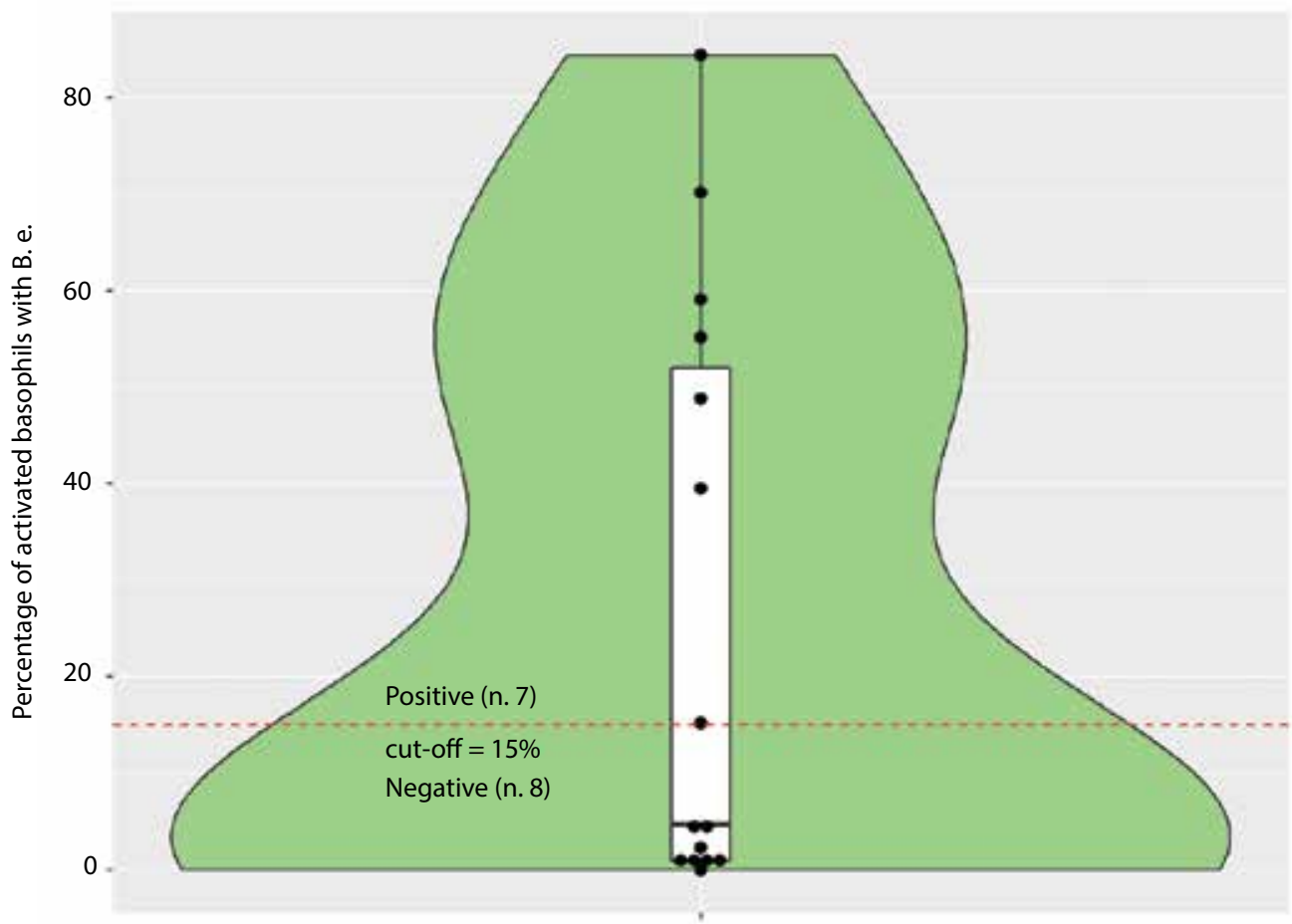


Figure 3 - Cross-reactivity of Anisakis whole extracts. IgE reactivity to Anisakis ImmunoCAP (P4) competitively inhibited by pre-incubation of serum with various concentrations of $A$.p.e and A.s.e extracts.

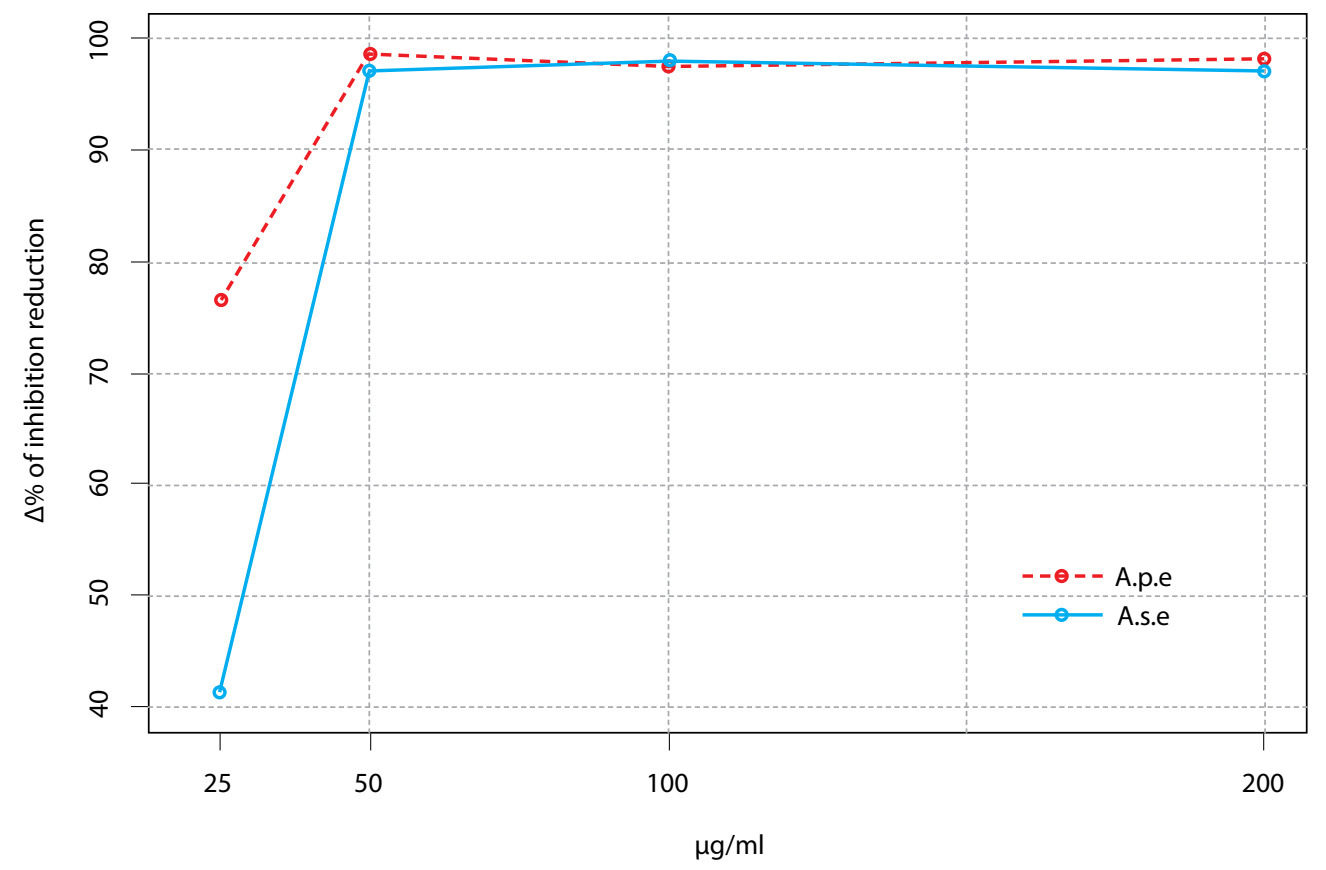

diagnostic approach, we documented an Anisakis sensitization prevalence of $10.9 \%$, being slightly lower than seroprevalence reported in previous studies conducted in Spain and Italy, ranging from $12.7 \%$ to $15.4 \%(9,31,36)$. Of interest, studies conducted in Italy showed a higher prevalence of sensitization to Anisakis in coastal areas and in large cities, probably due to culinary traditions and imported food habits. This is particularly true in the island of Sicily, where the main cities overlook the sea and the gastronomic tradition includes an intake of raw fish products (marinated anchovies or salted sardines), considered to be a potential cause of sensitization to Anisakis. This evidence was confirmed by our findings as recruited outpatients with an anamnesis suggestive of AS were more frequently residents in coastal areas as compared to ones affected by CU. Another documented risk factor to be taken into account in these areas at very high vocation to sea fish industry and commercial distribution is the occupational exposure, particularly involving anglers, fishermen and fishmongers (37).

Recent studies have found a significant association between chronic urticaria and positivity to Anisakis diagnosed with currently used tests (31,38-40), suggesting the contribution of Anisakis hypersensitivity in individuals with $\mathrm{CU}$, with a significant clinical improvement after a fish-free diet (31,38-41).
Our results showed a lower prevalence of Anisakis positivity in individuals with $\mathrm{CU}$ as compared to the mentioned studies, being these differences probably related to the eating habits of the populations in the study, as previously pointed out.

The prevalence of Anisakis sensitization obtained with the classic approach did not match with the real clinical prevalence, since $8.8 \%$ of those positive to specific IgE determination consisted of subjects with CU and 79.4\% (n. 50/63) of all the IgE positivity were related to cross-reactivity events (positivity to tropomyosin or to Ascaris allergens). Therefore, an overall genuine positivity was found in $2.3 \%$ of all the outpatients recruited in our study, with a higher significative prevalence in AS group as compared to $\mathrm{CU}$ group. Moreover, we haven't found any statistically significant difference between AS and CU outpatients with regard to cross reactive molecular sensitization, giving consistence to the previous result.

Preliminary studies supported in vitro use of Anisakis-related allergens for BAT, arguing that this method may replace the challenge test in vivo $(8,31-32)$ given its high specificity. Nevertheless, these studies provided data obtained with Anisakis simplex extract without specifying the different species $(8,10,31-32)$. Another limitation of those studied was due to the experimental designs, involving healthy patients as controls, which could 
represent a control group with a small statistical significance according to Anisakis seroprevalence in the general population. Our experimental analysis confirmed the high clinical specificity of BAT even in subjects with spontaneous CU not related to fish ingestion. More in depth, BAT confirmed the sensitization to Anisakis allergens in 8 subjects. Of these, 5 outpatients showed urticaria-angioedema or 3rd degree anaphylaxis after the ingestion of fish or cephalopods and 3 presented a clear medical history, even if they did not consume fish products. Of interest, one outpatient sensitized to tropomyosin showed positivity to A.p.e also but at the highest allergen concentrations (112.5 ng/ $\mathrm{ml}$ ), while another one, negative both to SPT and specific IgE, tested positive to BAT. This diagnostic aspect has already been described with regard to other food allergens (40-41). Furthermore, despite the fact that the BAT positive subjects showed a higher percentage of basophils activated with $A$. pegreffi $i$ allergens than with $A$. simplex s.s., the sensitivity of the test was not affected. On the other hand the ImmunoCAP inhibition test highlighted a lower blockage determined by A.s.e, suggesting that the A. pregreffi $i$ was the main source of the primary sensitization in the population studied. Lastly, we are not able to explain our finding documenting that B.e. tents to be a greater basophil activator as compared to the homemade extracts at some specific concentrations because we do not have any information about the Anisakis species and the molecular pattern of the preparation. At present, there are no clear guidelines on dietary restrictions for patients with Anisakis hypersensitivity. Several allergens of Anisakis are heath stable proteins (14-18), although some authors have reported a clinical improvement in patients sensitized to Anisakis after avoiding fish or consuming only frozen or wellcooked fish products during the follow-up $(31,43)$. Therefore, the preliminary data provided by the present work could be

\section{References}

1. European Food Safety Authority (EFSA) (2010) Scientific Opinion on risk assessment of parasites in fishery products and EFSA Panel on Biological Hazards (BIOHAZ). EFSA Journal 8:1543-1634.

2. Baird FJ, Gasser RB, Jabbar A, Lopata AL. Foodborne anisakiasis and allergy Mol Cell Probes 2014; 28 (4):167-174.

3. Pravettoni V, Primavesi L, Piantanida M. Anisakis simplex: current knowledge. Eur Ann Allergy Clin Immunol. 2012; 44(4):150-156.

4. Abattouy N, Valero A, Martín-Sánchez J, Peñalver MC, Lozano J. (2012) Sensitization to Anisakis simplex species in the population of northern Morocco J Investig Allergol Clin Immunol. 2012; 22(7):514-519.

5. Del Rey Moreno A, Valero A, Mayorga C, et al. Sensitization to Anisakis simplex s.l. in a healthy population Acta Trop. 2006; 97(3):265-269.

6. Mladineo I, Poljak V, Martínez-Sernández V, Ubeira FM. Anti-Anisakis IgE seroprevalence in the healthy Croatian coastal population and associated risk factors PLoS Negl Trop Dis. 2014; 6;8(2):e2673. useful for the development of clinical guidelines and to address future studies to provide more affordable evidences in support of public health strategies to be implemented in order to reduce the health risk related to Anisakis exposure (44).

In conclusion, our preliminary findings confirm the high specificity of BAT in the detection of Anisakis sensitization, supporting at the same time the opportunity to implement a comprehensive diagnostic algorithm for Anisakis allergy, including anamnesis, SPT and the determination of specific IgE for Anisakis, Ascaris and tropomyosin, as a first approach, followed by the use of BAT as confirmatory analysis. Moreover, the BAT should be performed in patients highly suspected of Anisakis allergy as well, despite testing negative to both SPT and specific IgE. Nevertheless, the not automatized execution and the relative high cost of this test suggest not to apply the BAT for every suspected Anisakis allergy case, then supporting the use of the proposed diagnostic comprehensive algorithm.

Last but not least, to the best of our knowledge, the findings of this preliminary study documented for the first time a difference in the prevalence of sensitivity in favor of $A$. pegreffi $i$ than $A$. simplex s.s. that could be related to a higher consumption of fish from the Mediterranean Sea, where this species of parasite is the most represented. This evidence should be taken into account when using the proposed diagnosis algorithm.

However, further studies on more consistent samples should be performed in order to confirm all the evidences provided and, particularly, to validate the proposed comprehensive diagnostic algorithm.

\section{Conflict of interests}

The authors declare that they have no conflict of interests.

7. Purello-D'Ambrosio F, Pastorello E, Gangemi S, et al. Incidence of sensitivity to Anisakis simplex in a risk population of fishermen/ fishmongers. Ann Allergy Asthma Immunol. 2000; 84(4):439-444.

8. Gamboa PM, Asturias J, Martínez R, et al. Diagnostic utility of components in allergy to Anisakis simplex J Investig Allergol Clin Immunol. 2012; 22(1):13-19

9. Martínez-Aranguren RM, Gamboa PM, García-Lirio E, Asturias J, Goikoetxea MJ, Sanz ML. In vivo and in vitro testing with rAni s 1 can facilitate diagnosis of Anisakis simplex allergy J Investig Allergol Clin Immunol. 2014; 24(6):431-438

10. Costa A, Cammilleri G, Graci S, et al. Survey on the presence of A. simplex s.s. and A. pegreffii hybrid forms in Central-Western Mediterranean Sea. Parasitol Int 2016; 65(6 Pt A):696-701

11. AAITO-IFIACI Anisakis Consortium. Anisakis hypersensitivity in Italy: prevalence and clinical features: a multicenter study Allergy. 2011; 66(12):1563-1569.

12. Sakanari J.A, Mckerrow J H. Anisakiasis. Clinical Microbiology Reviews. 1989; 2:278-284 
13. Cuéllar C, Daschner A, Valls A, De Frutos C, et al. Ani s 1 and Ani s 7 recombinant allergens are able to differentiate distinct Anisakis simplex-associated allergic clinical disorders Arch Dermatol Res.2012; 304(4):283-288

14. Vidaček S, De Las Heras C, Solas MT, García ML, Mendizábal A, Tejada M. Viability and antigenicity of anisakis simplex after conventional and microwave heating at fixed temperatures J Food Prot. 2011; 74(12):2119-2126.

15. Tejada M, Olivares F, de las Heras C, et al. Antigenicity of Anisakis simplex s.s. L3 in parasitized fish after heating conditions used in the canning processing J Sci Food Agric. 2015; 30;95(5):922-7.

16. Carballeda-Sangiao N, Olivares F, Rodriguez-Mahillo AI, et al. (2014) Identification of autoclave-resistant Anisakis simplex allergens. J Food Prot. 77(4):605-9

17. Asturias JA, Gómez-Bayón N, Arilla MC, et al. (1999) Molecular characterization of American cockroach tropomyosin (Periplaneta americana allergen 7), a cross-reactive allergen J Immunol.162:4342-4348

18. Johansson E., Aponno M., Lundberg M., Van Hage-Hamsten M. Allergenic cross-reactivity between the nematode Anisakis simplex and the dust mites Acarus siro, Lepidoglyphus destructor, Tyrophagus putrescentiae, and Dermatophagoides pteronyssinus Allergy. 2001; 56:660-666.

19. Lorenzo S, Iglesias R, Paniagua E, Ansotegui I, Alonso JM, Ubeira FM. Natural antibodies to nematode biotinyl-enzymes in human sera Med Microbiol Immunol.2001; 189(4):177-183

20. Petithory JC. New data on anisakiasis Bull Acad Natl Med. 2007;191(1):53-65

21. Pasolini B, Alessi E, De Medici D. Rapporto ISTISAN 05/24 Workshop di aggiornamento su problematiche emergenti nel settore dei prodotti ittici. 2004

22. Caballero ML, Asero R, Antonicelli L, et al. Anisakis allergy component-resolved diagnosis: clinical and immunologic differences between patients from Italy and Spain Int Arch Allergy Immunol. 2013; 162(1):39-44

23. Reese G, Ayuso R, Lehrer SB. Tropomyosin: an invertebrate panallergen Int Arch Allergy Immunol.1999; 119:247-258.

24. Carballeda-Sangiao N, Rodríguez-Mahillo AI, Puente S, Gutiérrez MT, Moneo I, González-Muñoz M. Anisakis/Ascaris IgE ratio improves specificity for the diagnosis of Anisakis simplex sensitization in travellers and immigrants Acta Trop. 2014; 138:1-4.

25. Del Pozo MD, Moneo I, Fernández de Corres L, et al. Laboratory determination in Anisakis simplex allergy J Allergy Clin Immunol. 1996; 97:977-984

26. Del Pozo MD, Audícana M, Diez JM, et al. Anisakis simplex, a relevant etiologic factor in acute urticaria Allergy. 1997; 52(5):576-9

27. García M, Moneo I, Audicana MT, et al. The use of IgE immunoblotting as a diagnostic tool in Anisakis simplex allergy J Allergy Clin Immunol. 1997; 99(4):497-501.

28. Lorenzo S, Iglesias R, Leiro J, et al. Usefulness currently available methods for the diagnosis of Anisakis simplex allergy Allergy 2000; 55(7):627-633.
29. Sastre J, Lluch-Bernal M, Quirce S, et al. A double blind, placebo-controlled oral challenge study with lyophilized larvae and antigen of the fish parasite, Anisakis simplex Allergy 2000; 55:560564.

30. Lluch-Bernal M, Sastre J, Fernández-Caldas E, et al. Conjunctival provocation tests in the diagnosis of Anisakis simplex hypersensitivity J Investig Allergol Clin Immunol. 2002; 12(1):21-24.

31. Frezzolini A, Cadoni S, De Pita O. Usefulness of the CD63 basophil activation test in detecting anisakis hypersensitivity in patients with chronic urticaria: diagnosis and follow-up Clin Exp Dermatol. 20120; 35(7):765-770.

32. Gonzalez-Muñoz M, Luque R, Nauwelaers F, Moneo I. (2005) Detection of Anisakis simplex-induced basophil activation by flow cytometry Cytometry B Clin Cytom. 2005; 68(1):31-66.

33. Heffler E, Sberna ME, Sichili S, et al. High prevalence of Anisakis simplex hypersensitivity and allergy in Sicily, Italy. Ann Allergy Asthma Immunol. 2016; 116:146-150.

34. Ludovisi A, Di Felice G, Carballeda-Sangiao N, et al. Allergenic activity of Pseudoterranova decipiens (Nematoda: Anisakidae) in BALB/c mice Parasit Vectors.2017; 12;10(1):290.

35. Savi E, Incorvaia C, Boni E, Mauro M, Peveri S, Pravettoni V, Quercia O, Reccardini F, Montagni M, Pessina L, Ridolo. E Which immunotherapy product is better for patients allergic to Polistes venom? A laboratory and clinical study PLoS One. 2017; 7;12(7):e0180270

36. Baeza ML, Zubeldia JM, Rubio M. Anisakis simplex allergy. ACI Int; 2001; 13:242-249.

37. Mazzucco W, Lacca G, Cusimano R, et al. Prevalence of sensitisation to Anisakis simplex among professionally exposed populations in Sicily Arch Environ Occup Health 2012; 67:91-97

38. Daschner A, De Frutos C, Valls A, Vega F. Anisakis simplex sensitization-associated urticaria: short-lived immediate type or prolonged acute urticaria Arch Dermatol Res. 2010; 302(8):625-694

39. Daschner A, Rodero M, DE Frutos C, et al. Different serum cytokine levels in chronic vs. acute Anisakis simplex sensitization-associated urticaria Parasite Immunol.2011; 33(6):357-362

40. Daschner A, Fernández-Fígares V, Valls A, et al. Different fish-eating habits and cytokine production in chronic urticaria with and without sensitization against the fish-parasite Anisakis simplex Allergol Int. 2013; 62(2):191-201

41. Kim JH, An S, Kim JE, Choi GS, Ye YM, Park HS. Beef-induced anaphylaxis confirmed by the basophil activation test Allergy Asthma Immunol Res.2010; 2(3):206-208

42. Raap U, Wieczorek D, Schenck F, Kapp A, Wedi B. The basophil activation test is a helpful diagnostic tool in anaphylaxis to sesame with false-negative specific IgE and negative skin test Allergy. 2011; 66(11):1497-1499

43. Ventura MT, Napolitano S, Menga R, Cecere R, Asero R. Anisakis simplex hypersensitivity is associated with chronic urticaria in endemic areas. Int Arch Allergy Immunol. 2013; 160:297-300.

44. Mazzucco W, Raia DD, Marotta C, et al. Anisakis sensitization in different population groups and public health impact: A systematic review. PLoS One. 2018;13(9):e0203671 